\title{
Chondrogenesis, osteogenesis and adipogenesis of canine mesenchymal stem cells: a biochemical, morphological and ultrastructural study
}

\author{
C. Csaki · U. Matis · A. Mobasheri · H. Ye • \\ M. Shakibaei
}

\begin{abstract}
Musculoskeletal diseases with osteochondrotic articular cartilage defects, such as osteoarthritis, are an increasing problem for humans and companion animals which necessitates the development of novel and improved therapeutic strategies. Canine mesenchymal stem cells (cMSCs) offer significant promise as a multipotent source for cell-based therapies and could form the basis for the differentiation and cultivation of tissue grafts to replace damaged tissue. However, no comprehensive analysis has been undertaken to characterize the ultrastructure of in vitro differentiated cMSCs. The main goal of this paper was to focus on cMSCs and to analyse their differentiation capacity. To achieve this aim, bone marrow cMSCs from three canine patients were isolated, expanded in monolayer culture and characterized with respect to their ability for osteogenic, adipogenic and chondrogenic differentiation capacities. cMSCs showed proliferative potential and were capable of osteogenic, adipogenic and
\end{abstract}

The research was conducted in part for the doctoral thesis of Han Ye to be submitted to Fachbereich Humanmedizin, Institut of Anatomy, Ludwig-Maximilians University Munich, Germany.

C. Csaki $\cdot$ H. Ye $\cdot$ M. Shakibaei $(\bowtie)$

Institute of Anatomy, Musculoskeletal Research Group,

Ludwig-Maximilian-University Munich,

Pettenkoferstrasse 11, 80336 Munich, Germany

e-mail: mehdi.shakibaei@med.uni-muenchen.de

U. Matis

Clinic of Veterinary Surgery,

Ludwig-Maximilians-University Munich,

Munich, Germany

\section{A. Mobasheri}

Division of Veterinary Medicine,

School of Veterinary Medicine and Science,

University of Nottingham, Sutton Bonington Campus,

Loughborough, LE12 5RD, UK chondrogenic differentiation. cMSCs treated with the osteogenic induction medium differentiated into osteoblasts, produced typical bone matrix components, $\beta 1$-integrins and upregulated the osteogenic specific transcription factor Cbfa- 1 . cMSCs treated with the adipogenic induction medium showed typical adipocyte morphology, produced adiponectin, collagen type I and $\beta 1$-integrins, and upregulated the adipogenic specific transcription factor PPAR $-\gamma$. cMSCs treated with the chondrogenic induction medium exhibited a round to oval shape, produced a cartilage-specific extracellular matrix, $\beta 1$-integrins and upregulated the chondrogenic specific transcription factor Sox9. These results demonstrate, at the biochemical, morphological and ultrastructural levels, the multipotency of cMSCs and thus highlight their potential therapeutic value for cell-based tissue engineering.

Keywords Mesenchymal stem cells · Chondrogenesis · Adipogenesis · Osteogenesis · Ultrastructure

\section{Introduction}

Stem cells are defined as undifferentiated cells from the embryo, fetus or adult that have the unique potential to generate various differentiated tissue cells under appropriate biochemical, hormonal and mechanical stimuli in vitro and in vivo (Caplan 1991; Caplan and Bruder 2001). Adult stem cells in particular, represent a promising model for regenerative medicine and tissue engineering because the use of embryonic and fetal stem cells is limited by ethical considerations (Lee and Hui 2006; Leo and Grande 2006). In contrast to embryonic and fetal stem cells, which are pluripotent, adult stem cells are multipotent, unspecialized cells that have been identified in various tissues and organs. They can serve as a multipotent reservoir to replenish specific tissue cells 
when they die (Caplan and Dennis 2006; Fuchs et al. 2004). Adult stem cells have been isolated from a variety of tissues and organs including peripheral blood (Till and McCulloch 1980), adipose tissue (Wickham et al. 2003; Zuk et al. 2001), central nervous system (Bottai et al. 2003; Alexanian and Sieber-Blum 2003), muscle (Williams et al. 1999) and bone marrow (Caplan 1991). Bone marrow hosts not only hematopoetic stem cells but it also contains a mesenchymal fibroblastic cell type that can differentiate into bone, fat and cartilage in vitro (Pittenger et al. 1999). There are no mesenchymal stem cell (MSC)-specific cellular markers, therefore their identification is achieved through their ability to adhere to plastic in vitro, through their multilineage differentiation potential in vitro and through a combination of positive expression or distinct lack of defined cell surface markers (Conget and Minguell 1999; Jaiswal et al. 1997; Dominici et al. 2006). These markers include $\mathrm{CD} 105^{+}, \mathrm{CD} 3^{+}$and $\mathrm{CD}^{+}$, whereas MSCs should lack CD45 ${ }^{-}, \mathrm{CD}^{-} 4^{-}$and several other hematopoetic stem cell markers (Dominici et al. 2006). Numerous studies have advanced our understanding of these MSCs, their phenotype, multilineage differentiation potential and possible clinical applications (Cancedda et al. 2003; Caplan and Dennis 2006; Tuan 2006; Giordano et al. 2007). Whilst human, horse, pig and bovine MSCs have been investigated, most of these studies have been performed on small experimental animals such as rabbits and mice (Bosnakovski et al. 2005; Fortier et al. 1998; Majumdar et al. 2000; Johnstone et al. 1998; Ringe et al. 2002; Harris et al. 2004). The dog offers not only a valuable experimental model but also represents a clinically important patient and welfare concern. Little research has been done with canine MSCs (cMSCs) to date. Current studies have mainly focused on the osteogenic potential of cMSCs in vitro and in vivo (Kadiyala et al. 1997). However, the additional knowledge of differentiating and manipulating cMSCs into various other tissues holds a promising key for cell based tissue repair and tissue engineering. Therefore, in order to assess the potential of cMSCs in future clinical applications, it is essential to gain more insight into their differentiation capacity and evaluate the tissues formed by these cells at the biochemical, ultrastructural and immunomorphological levels.

In the present study, we investigated the biochemical, morphological and ultrastructural characteristics of the newly formed tissue by canine bone marrow derived MSCs induced towards osteogenic, adipogenic and chondrogenic lineages.

\section{Materials and methods}

\section{Antibodies}

Polyclonal anti-collagen type II antibody (PAB746), polyclonal anti-collagen type I antibody (PAB749P), monoclonal anti-adult cartilage-specific proteoglycan antibody (MAB2015), monoclonal anti- $\beta 1$-integrin antibody (MAB1965), polyclonal anti-osteocalcin antibody (PAB1857) and alkaline phosphatase linked sheep antimouse (AP303A) and sheep anti-rabbit secondary antibodies (AP304A) for immunoblotting and immunoelectron labelling were purchased from Chemicon International, Inc., (Temecula, CA, USA). Polyclonal anti-Cbfa-1 (CBFA11-A) and polyclonal anti-adiponectin (ACRP302-S) were purchased from Alpha Diagnostics Int. San Antonio, TX, USA. Monoclonal anti- $\beta$-Actin (A4700) was purchased from Sigma, St. Louis, MO, USA). Monoclonal anti-sox9 (H00006662-M01), polyclonal anti-PPAR (SP5301P), monoclonal anti-CD105 (BM2221), monoclonal anti-CD90 (BM2343), monoclonal anti-CD45 (SM3025) and monoclonal anti-CD34 (SM1095) antibodies were purchased from Acris Antibodies GmbH, Germany.

\section{Stem cell isolation}

Bone marrow aspirates were collected under sterile conditions from the femoral neck of three different dogs undergoing total hip replacement and diluted with $3 \%$ citrate. Before further processing the samples were diluted 1:1 with sterile Hanks salt solution, transferred over to $15 \mathrm{ml}$ of Ficoll-paque (Amersham Bioscience, No. 17-1440-02) and centrifuged at $400 \mathrm{~g} / 20^{\circ} \mathrm{C}$ for $30 \mathrm{~min}$. The middle layer was transferred to a new tube and diluted with Hanks salt solution. The suspension was then centrifuged again at $450 \mathrm{~g} /$ $20^{\circ} \mathrm{C} / 5 \mathrm{~min}$ and the supernatant was discarded. Cells were washed three times and seeded in a T75 flask with cell culture medium consisting of DMEM/Hams-F12 1:1, $10 \%$ fetal calf serum (FCS), $1 \%$ partricin solution, $1 \%$ penicillin/ streptomycin solution (10,000 IU/10,000 IU), $75 \mu \mathrm{g} / \mathrm{ml}$ ascorbic acid, $1 \%$ essential amino acids and $1 \%$ glutamine, all obtained from Seromed (Munich, FRG) and incubated at $37^{\circ} \mathrm{C} / 5 \% \quad \mathrm{CO}_{2}$. After 4 days the non-adherent cells were washed away with Hanks salt solution and the flasks containing the adherent cells were retained and incubated further. The culture medium was changed three times per week. The cells were split for the first time after about 1 week when colonies of fibroblast-like cells had formed. After this, cells were split when they reached 60-70\% confluency. Overall the cells were passaged three to four times.

\section{Experimental design}

\section{Osteogenesis}

Osteogenic differentiation was performed in monolayer culture and in high density mass culture. For monolayer culture 20,000 cells were seeded per well in a six-well-plate 
and cultured until confluent. The high density mass culture was performed on a steel grid bridge as previously described by Shakibaei (1998). Briefly, a cellulose filter was placed on the bridge, onto which an $8 \mu$ l suspension of cells, containing about 1 million cells, was placed. Culture medium reached the filter and the cells were nurtured at the filter-medium interface through diffusion. After 1 day in culture the cells formed a three-dimensional pellet on the filter. The osteogenic induction medium was prepared as described by Pittenger et al. (1999), consisting of DMEM base medium, $10 \% \mathrm{FCS}$, penicillin/streptomycin solution (10,000 IU/10,000 IU/100 ml), $10^{-7} \mathrm{M}$ dexamethasone (Sigma, Cat. No. D-8893), $10 \mathrm{mM} \beta$-glycerophosphate (Sigma, Cat. No. G-9891) and $50 \mu \mathrm{M}$ ascorbate-2-phosphate (Sigma, Cat. No. A-8960). Medium changes were made every 3 days. Negative control cells were maintained in cell culture medium containing $10 \%$ FCS.

\section{Adipogenesis}

Adipogenic differentiation was performed in monolayer culture in six-well-plates as described by Pittenger et al. (1999). Briefly, 20,000 cells were seeded per well and cultured until confluency. The cells were then treated for $72 \mathrm{~h}$ with the adipogenic induction medium consisting of DMEM base medium, 10\% FCS, penicillin/streptomycin solution $(10,000 \mathrm{IU} / 10,000 \mathrm{IU} / 100 \mathrm{ml}), 1 \mu \mathrm{M}$ dexamethasone (Sigma, Cat. No. D-8893), $0.2 \mathrm{mM}$ Indomethacin (Sigma, Cat. No. I-5879), $0.1 \mathrm{mg} / \mathrm{ml}$ insulin (Sigma, Cat. No. I-0516), $1 \mathrm{mM}$ 3-isobutyl-1-methylxanthin (IBMX) (Sigma, Cat. No. I-7378) and afterwards for $24 \mathrm{~h}$ with adipogenic maintenance medium consisting of DMEM base medium, $10 \%$ FCS, penicillin/streptomycin solution $(10,000 \mathrm{IU} / 10,000 \mathrm{IU} / 100 \mathrm{ml})$ and $0.1 \mathrm{mg} / \mathrm{ml}$ insulin. This cycle was repeated four times. Afterwards the cells were cultured for one more week in adipogenic maintenance medium. For the negative control cells were cultured in cell culture medium containing $10 \%$ FCS.

\section{Chondrogenesis}

Chondrogenic differentiation was performed with two different three-dimensional culture methods: in high density mass-culture (Shakibaei et al. 1993), as described above, and in pellet culture (Pittenger et al. 1999). Approximately 250,000 cells were centrifuged in a conical tube to achieve mass pellet culture. The cultures were incubated for 14 days with a chondrogenic differentiation medium as described by Pittenger et al. (1999) consisting of DMEM base medium, D-(+)-glucose $0.35 \mathrm{~g} / 100 \mathrm{ml}$ (Sigma, Cat No. G7021), ITS + 1 liquid media supplement $[10 \mu \mathrm{g} / \mathrm{ml}$ insulin, $5.5 \mu \mathrm{g} / \mathrm{ml}$ transferrin, $5 \mathrm{ng} / \mathrm{ml}$ selenium, $0.5 \mathrm{mg} / \mathrm{ml}$ bovine albumin, $4.7 \mu \mathrm{g} / \mathrm{ml}$ linoleic acid (Sigma, Cat. No.
I-2521)], $0.1 \mathrm{mM}$ ascorbate-2-phosphate (Sigma, Cat. No. A-8960), $10^{-7} \mathrm{M}$ dexamethasone (Sigma, Cat. No. D-8893), penicillin/streptomycin solution (10,000 IU/10,000 IU/ $100 \mathrm{ml}$ ). $10 \mathrm{ng} / \mathrm{ml}$ hTGF $\beta 1$ (Acris Antibodies GmbH, Germany) was added fresh to the medium before each medium change. Medium changes were made every 3 days. The negative control followed the same protocol except that the chondrogenic differentiation medium contained no hTGF $\beta 1$ or consisted of cell culture medium with $10 \%$ FCS.

\section{Light microscopy}

Monolayer cultures treated with osteogenic differentiation medium were stained with von Kossa for mineralized matrix deposition. Briefly, cultures were first fixed for $10 \mathrm{~min}$ in methanol, washed three times with aqua dest., incubated for $1 \mathrm{~h}$ with silver nitrate solution in the dark, again washed with aqua dest, incubated with pyrogallic acid $1 \%$ for $5 \mathrm{~min}$, washed with aqua dest., fixed with sodium thiosulfate solution $5 \%$ and counterstained with nuclear fast red-solution $0.1 \%$ to visualize the cell nuclei.

Monolayer cultures treated with adipogenic differentiation medium were stained with Oil Red O solution to visualize the formation of fat vacuoles. Briefly, the cultures were fixed with ice-cold formalin $3 \%$, washed for $2 \mathrm{~min}$ with ice-cold alcohol $50 \%$, incubated for 20 min with $0.2 \%$ Oil Red O solution and washed with tap water.

High density cultures treated with chondrogenic differentiation medium were embedded in Tissue-Tek (Sakura Finetek Europe, The Netherlands), cryopreserved at $-80^{\circ} \mathrm{C}$ and cut into $5-7 \mu \mathrm{m}$ sections using a cryomicrotome (Zeiss, Germany). Sections were mounted on Superfrost plus slides (Menzel-Glaeser, Germany), air-dried and fixed in acetone for $20 \mathrm{~s}$ before staining with alcian blue $(0.05 \%$ alcian blue in $3 \%$ acetic acid ( $\mathrm{pH} 1.5$ ) plus $0.3 \mathrm{M} \mathrm{MgCl}_{2}$ ) for $2 \mathrm{~h}$ to detect extracellularly deposited cartilage specific proteoglycans (CSPG).

All cultures were evaluated under a light microscope (Leica, Germany) and the photomicrographs were digitally acquired.

\section{Immunofluorescence}

Isolated canine bone marrow MSCs in monolayer cultures were evaluated by immunofluorescence microscopy for MSC specific markers $\mathrm{CD}_{105^{+}}$and $\mathrm{CD} 0^{+}$and for hematopoetic stem cell markers $\mathrm{CD} 45^{-}$and $\mathrm{CD} 34^{-}$. Expression of $\beta 1$-integrins and $\beta$-actin in monolayer culture of MSCs was also evaluated using this technique.

\section{Transmission electron microscopy (TEM)}

Transmission electron microscopy was performed as described by Shakibaei et al. (1997). Briefly, cultures were 
fixed in Karnowsky fixative for $1 \mathrm{~h}$, washed three times with $0.1 \mathrm{M}$ phosphate buffered saline (PBS) and incubated for $2 \mathrm{~h}$ with $4 \%$ Osmium. After additional washing in PBS, the cultures were dehydrated in an ascending alcohol series and embedded in Epon (Plano, Marburg, FRG). Ultrathin sections of the cultures were prepared and evaluated with a transmission electron microscope (Zeiss, Germany).

Immuno-transmission electron microscopy

(ITEM, post-embedding technique)

Immuno-electron microscopy was performed as described in detail by Shakibaei (1998). Briefly, cultures were fixed for $1 \mathrm{~h}$ in $3 \%$ freshly prepared formaldehyde (paraformaldehyde plus $0.25 \%$ glutaraldehyde), washed three times with $0.1 \mathrm{M}$ PBS, dehydrated in an ascending alcohol series and embedded in LR-white (Plano, Marburg, FRG). Ultrathin sections of the cultures were prepared and treated as follows: (1) Bovine serum albumin (BSA) $1 \%$ at ambient temperature (AT) for $30 \mathrm{~min}$; (2) testicular chondroitinase $(5,000 \mathrm{U} / \mathrm{ml})$ for $5 \mathrm{~min}$ to unmask epitopes; (3) PBS/ BSA1\%/Tween $200.5 \% 2 \times 5$ min at AT; (4) primary antibodies (1:50 in PBS/BSA) over night at $4{ }^{\circ} \mathrm{C}$; (5) PBS/BSA $2 \times 5 \mathrm{~min}$ at AT; (6) secondary antibodies conjugated with goat anti-rabbit immunoglobulin with $10 \mathrm{~nm}$ gold particles (1:50 for $30 \mathrm{~min}$ ) at $\mathrm{AT}$; (7) after rinsing for $2 \times 5 \mathrm{~min}$ at AT; (8) contrasting was carried out with tannic acid $1 \%$ for 20 min at AT, with Osmium $4 \%$ for 10 min and with uranyl acetate $2 \%$ for $30 \mathrm{~min}$. Finally, the sections were rinsed and examined under a transmission electron microscope (Zeiss, Germany).

\section{Immunoblotting}

To extract proteins for immunoblotting the cultures were treated on ice for $30 \mathrm{~min}$ with lysis buffer $(50 \mathrm{mM}$ Tris/ $\mathrm{HCl}$, pH 7.2/150 mM NaCl/(v/v) Triton X-100/1 mM sodium orthovanadate $/ 50 \mathrm{mM}$ sodium pyrpphosphate/ $100 \mathrm{mM}$ sodium fluoride $/ 4 \mu \mathrm{g} / \mathrm{ml}$ pepstatin $\mathrm{A} / 1 \mathrm{mM}$ PMSF). After centrifugation at $9,000 \mathrm{~g}$ for $30 \mathrm{~min}$ the supernatant was stored at $-80^{\circ} \mathrm{C}$ until further use. Total protein content of each lysate was determined according to the bicinchoninic acid system (Uptima, Interchim, Montlucon, France) using BSA as a standard. The lysates were further reduced with 2-mercaptoethanol on a heat block for $10 \mathrm{~min}$ at $90^{\circ} \mathrm{C}$ and after adjusting the equal amounts of total protein, were separated on $5,7.5$ or $10 \%$ polyacrylamide gels by SDS-page electrophoresis under reducing conditions (Mini Protean III, Bio-Rad-Laboratories, Munich, Germany). Proteins were then transferred onto a nitrocellulose membrane for $60 \mathrm{~min}$ at $120 \mathrm{~V}$ using a transblot electrophoresis apparatus (Mini Trans Blot, Bio-Rad-
Laboratories, Munich, Germany). Membranes were transferred to blocking buffer (skimmed milk powder in $1 \%$ PBS and Tween 20) for $2 \mathrm{~h}$ and then incubated overnight with the primary antibody at $4^{\circ} \mathrm{C}$. Membranes were further washed $3 \times 10 \mathrm{~min}$ in blocking buffer and then incubated with the secondary alkaline-phosphatase conjugated antibody for $1.5 \mathrm{~h}$. After repeated washing in $0.1 \mathrm{M}$ Tris buffer $\left(0.05 \mathrm{M} \mathrm{MgCl}_{2} / 0.1 \mathrm{M} \mathrm{NaCl}\right)$ specific binding was detected using nitro blue tetrazolium and 5-bromo-4-chloro-3indoyl-phosphate ( $p$-toluidine salt, Pierce Rockford, IL, USA) as substrates for alkaline phosphatase.

\section{Results}

Monolayer cell culture of isolated MSCs

In monolayer culture the isolated bone marrow MSCs assumed a polymorphic, fibroblast-like morphology. Colony formation was observed after 3-5 days in culture. The cells actively searched for cell-cell contacts. After 6-7 days in culture, the colonies became confluent and were passaged for the first time (Fig. 1a).

Immunofluorescence of MSCs in monolayer culture

The isolated MSCs showed a strong positive signal for the stem cell specific markers $\mathrm{CD} 105^{+}$and $\mathrm{CD}^{+} 0^{+}$(Fig. 1b, c). In contrast to this they were clearly labeled negative for the hematopoetic stem cell markers $\mathrm{CD}^{-} 5^{-}$and $\mathrm{CD} 34^{-}$ (Fig. 1d, e). Furthermore, MSCs in monolayer cultures were labeled positive for $\beta 1$-integrins (not shown), which mediate cell adhesion, convey transmembrane connections to the cytoskeleton and activate many intracellular signaling pathways (Buck and Horwitz 1987).

Multi-lineage differentiation potential of canine stem cells

The differentiation potential of the isolated canine bone marrow MSCs was tested by culturing under multi-differentiation conditions.

\section{A: Osteogenic differentiation capacity}

\section{Light microscopy}

To evaluate mineral deposition, osteogenic differentiation was performed in monolayer culture for 3 weeks. Cells were induced towards osteogenesis after reaching confluency. With the induction medium cells changed from a fibroblastic appearance to a more polygonal appearance and formed nodules. After 3 weeks culture time, the induced cells were stained positive with von Kossa stain for mineral 
Fig. 1 a Light microscopic demonstration of cMSCs in monolayer culture. In monolayer culture the isolated cMSCs assumed a polymorphic, fibroblast-like morphology. Colony formation was observed after $3-5$ days in culture. Cells actively searched for cell-to-cell contacts. After 6-7 days in culture, the colonies became confluent and were passaged for the first time. Magnification: $20 \times$. b-e Immunofluorescence labeling of isolated cMSCs. The isolated cMSCs showed a strong positive signal for the stem cell specific markers $\mathrm{CD}_{105^{+}}(\mathbf{b})$ and $\mathrm{CD} 90^{+}$ (c). Contrary to this, the hematopoetic stem cell markers $\mathrm{CD} 45^{-}$ (d) and CD34- (e) could not be detected. Magnification: $40 \times$
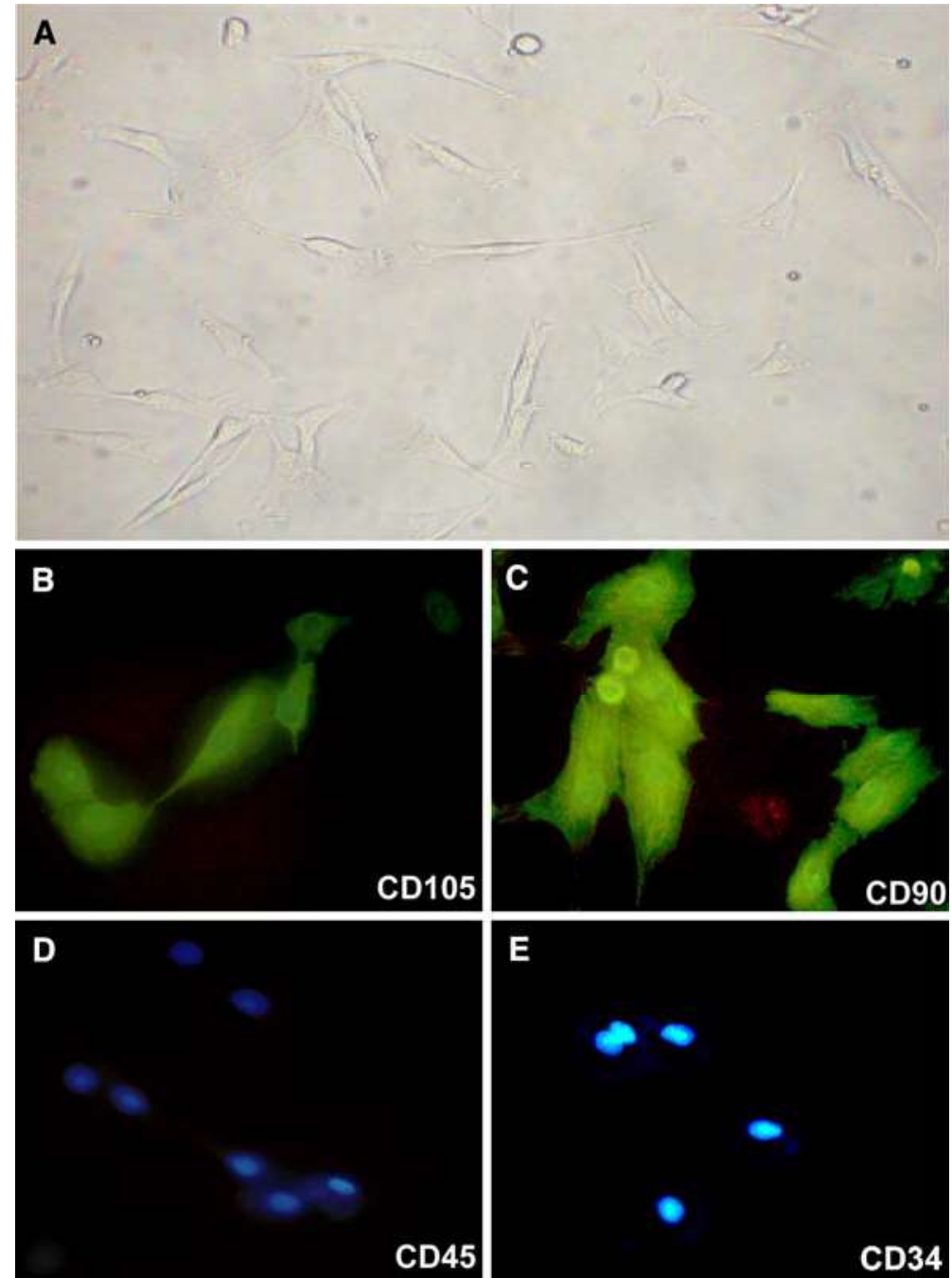

deposition in their newly formed matrix (Fig. 2a). Control cultures, although becoming over-confluent after 3 weeks, retained their fibroblast like appearance, did not form cell aggregates and were stained negative for mineral deposition (Fig. 2b).

\section{Transmission electron microscopy (TEM)}

Transmission electron microscopic images taken from the monolayer-induced cultures revealed details of the ultrastructural changes that the cMSCs underwent while transforming into osteoblasts. Cells were observed with high contents of euchromatin in their nucleus, a large number of cell organelles (mitochondria, rough ER, Golgi apparatus) and many cell-cell processes, all signs for a very active cell metabolism. Further large amounts of thick fibrils of well organized extracellular matrix could be observed in the extracellular space. Furthermore, these fibrils could also be detected as a thin pericellular hem on the outer membrane of the cells (Fig. 2c).
Immuno-transmission electron microscopy (ITEM)

To further characterize the composition of the newly formed extracellular matrix immuno-electron microscopy was performed which detected collagen type I, the most abundant collagen type found in bone matrix, and osteocalcin, an osteoblast specific protein (Fig. 3a, b). It was notable, that epitopes for collagen I were evenly distributed over the matrix and in contrast, epitopes for osteocalcin were bundled together in little groups, indicating the embedding of the osteocalcin protein between the mesh network of the large collagen type I fibers.

\section{Western blot analysis}

To confirm the immunomorphological results described above and to show more precisely the identity of the produced matrix by the newly formed osteoblasts, whole cell extracts were probed for collagen type I, Cbfa- 1 and $\beta 1$-integrin. High collagen type I content was detected by immunoblotting in the 

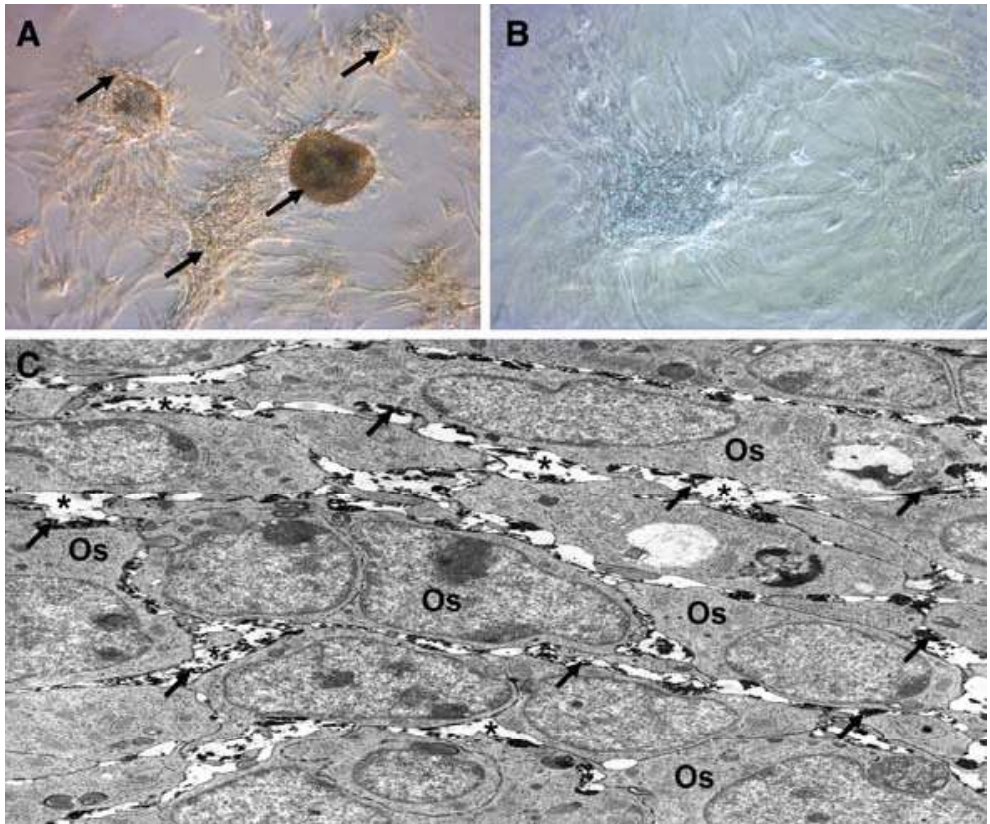

Fig. 2 a-b Light microscopic demonstration of osteoid-tissue formation with von Kossa staining. With the induction medium cells changed from a fibroblastic appearance to a more cuboidal appearance, were surrounded with an abundant matrix and formed mineralised nodules (a). After 3 weeks of culture time, the stimulated cells (a), in contrast to control cells (b), were stained positive with von Kossa stain for mineral deposition in their newly formed matrix (arrows). Control cultures, although becoming over-confluent after three weeks culture time, retained their fibroblast like appearance, did not form cells aggregates and were stained negative for mineral deposition. Magnification: $40 \times$. c Electron microscopic demonstration of the osteogenic induced

osteogenic-induced cultures as well as in the positive control probe of pure primary osteoblasts (Fig. 4a-I). Furthermore, immunoblotting with antibodies raised against $\beta 1$-integrin revealed high $\beta 1$-integrin expression in the osteogenic-induced and pure osteoblast cultures (Fig. $4 \mathrm{~b}-\mathrm{I}$ ). Since $\beta 1$-integrin is known to play an important role in cell-matrix interaction in connective tissue, such as cartilage (Shakibaei 1998) a similar mechanism may be active between cells and matrix in bone formation. Furthermore, the osteogenic specific transcription factor Cbfa-1 (Runx-2) was highly detected in the osteogenic induced cultures (Fig. 4c-I). In both control samples, monolayer and high density culture, the cMSCs were culture without the osteogenic induction medium, neither collagen type I production nor Cbfa-1 could be detected (Fig. 4a/c-I).

\section{B: Adipogenic differentiation capacity}

\section{Light microscopy}

Using phase contrast microscopy, cMSC monolayer cultures treated with adipogenic induction media were found to contain more vacuoles compared to the untreated control cells. Oil Red O staining for fat revealed, that these vacuoles
cMSCs. Transmission electron microscopic demonstration of the stimulated cultures revealed details of the ultrastructural changes the cMSCs underwent while transforming into osteoblasts $(O s)$. Cells are observed with high contents of euchromatin in their nucleus, a large number of cell organelles (mitochondria, rough ER, Golgi apparatus) and many cell-to-cell processes, all signs for a very active cell metabolism. Furthermore, large amounts of thick fibrils (arrows) of extracellular matrix can be observed in the extracellular space (asterisks). Indeed, these fibrils can also be detected as a thin pericellular hem on the outer membrane of the cells thus indicating the cells as the producers of this thick extracellular matrix. Magnification: $3,000 \times$

contain neutral lipids (Fig. 5a). In contrast to this, control cells cultured for the same time period in normal culture medium, containing $10 \%$ FCS, stained negative for fat vacuoles (Fig. 5b). Furthermore, in the induced cultures, Oil Red O staining could be found in nearly $80-90 \%$ of the cells. This demonstrates that adipogenic differentiation of the marrow cMSCs was highly efficient.

\section{Transmission electron microscopy (TEM)}

To evaluate the morphological features of the newly formed adipocytes, the cells were examined under electron microscopy. This ultrastructural examination by transmission electron microscopy, revealed a very high accumulation of lipid droplets in the cells (Fig. 5c). Indeed, after adipogenic induction for 23 days, the TEM confirmed $100 \%$ of the cMSCs possessed an adipogenic phenotype, exhibiting accumulated lipid droplets in their cytoplasm with well-developed rough endoplasmatic reticulum and mitochondria. Mitochondria in these newly formed adipocytes were densely packed, elongated, and large-sized. In addition, abundant lamellar cristae, which were rare in cMSCs, were observed in fully differentiated adipocytes, 


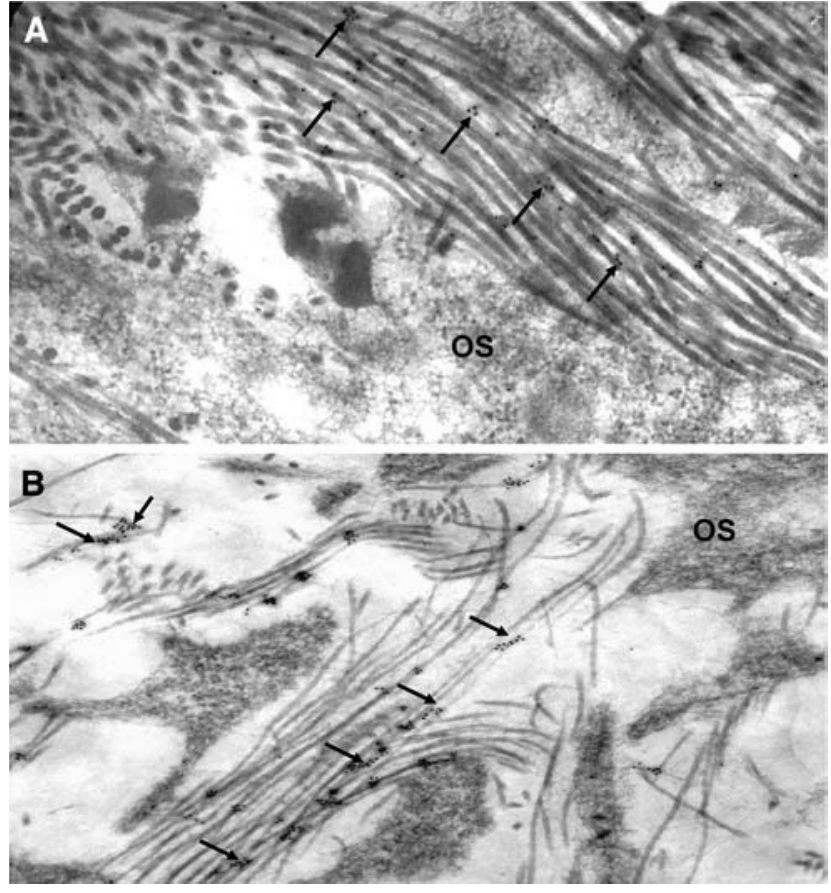

Fig. 3 a-b Transmission immuno-electron microscopic demonstration of collagen type I and osteocalcin in osteogenic induced cultures using immunogold labeling. a Immuno-labeling with collagen type I was only demonstrable on the thick fibrils (arrows). b Immuno-labeling with osteocalcin was distributed in the extracellular matrix. The gold particles (arrows) were bundled together in little groups, indicating the embedding of the osteocalcin protein between the mesh network of the large collagen type I fibres. Magnification: a-b 25,000×

suggesting that mitochondria in adipocytes are highly functional. Furthermore, adipocytes were embedded in large amounts of well organized extracellular matrix compounds.

\section{Immuno-transmission electron microscopy (ITEM)}

Characterization of this newly formed adipogenic extracellular matrix by immuno-electron microscopy revealed very clearly abundant amounts of collagen type I (Fig. 6a) and adiponectin, the most abundant protein in adipose tissue (Fig. 6b). It was observed that collagen type I epitopes were distributed evenly in the matrix, while adiponectin was bundled between the collagen type I mesh.

\section{Western blot analysis}

To confirm the immunomorphological results, Western blot analysis was performed and whole cell extracts were probed against adiponectin, peroxisome proliferator-activated receptor- $\gamma$ (PPAR $\gamma$ ), $\beta 1$-integrin and collagen type I. High amounts of adiponectin, the most abundant protein in adipose tissue and upregulation of the adipocyte specific transcription factor peroxisome proliferator-activated receptor- $\gamma$ (PPAR- $\gamma$ ) were detected in the adipogenic-induced cultures, comparable to the
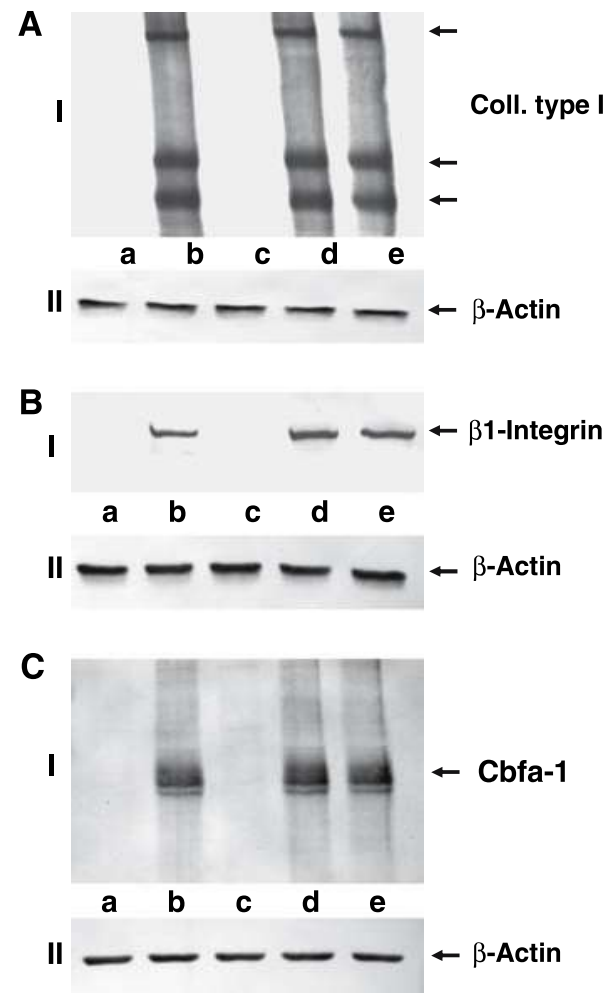

Fig. 4 a-c Western blot analysis of osteogenic induced cultures. Western blot analysis with whole cell extracts from monolayer cultures without (a) and with (b) osteogenic induction medium and from high density cultures without (c) and with (d) osteogenic induction medium and from a positive control of a pure primary osteoblast culture (e). Cell extracts were probed for expression of collagen type I $(A I, I I), \beta 1$ integrin $(B I, I I)$ and Cbfa-1 $(C I, I I)$ by Western blot analysis. Results of Western blot analysis revealed expression of collagen type I $(A I)$, $\beta 1$-integrin $(B I)$ and the osteogenic specific transcription factor Cbfa-1 $(C I)$ in with osteogenic medium induced monolayer and high density cultures $(A I-C I)$. In both negative control samples (without osteogenic induction medium), monolayer and high density culture, neither collagen type I, $\beta 1$-integrin expression nor Cbfa- 1 could be detected. Expression of $\beta$-actin $(A I-C I)$ was not affected. Data shown are representative of three independent experiments

amounts detected in a probe of pure primary isolated adipocytes (Fig. 7a/b-I). Furthermore, high content of $\beta 1$-integrin (Fig. 8b-I) was detected in the adipogenic-induced cultures as well as high levels of collagen type I (Fig. 8a-I). $\beta 1$-integrin and collagen type I were also detected in the pure primary adipocyte probes. Neither adiponectin, PPAR- $\gamma$ nor collagen type I could be detected in the monolayer control cells, cultured with normal cell culture medium with $10 \%$ FCS. However, $\beta 1$-integrin was detected in the control cultures.

\section{C: Chondrogenic differentiation capacity}

\section{Light microscopy}

cMSCs cultured with the chondrogenic induction medium containing dexamethasone and TGF $\beta$ - 1 , either cultured in 


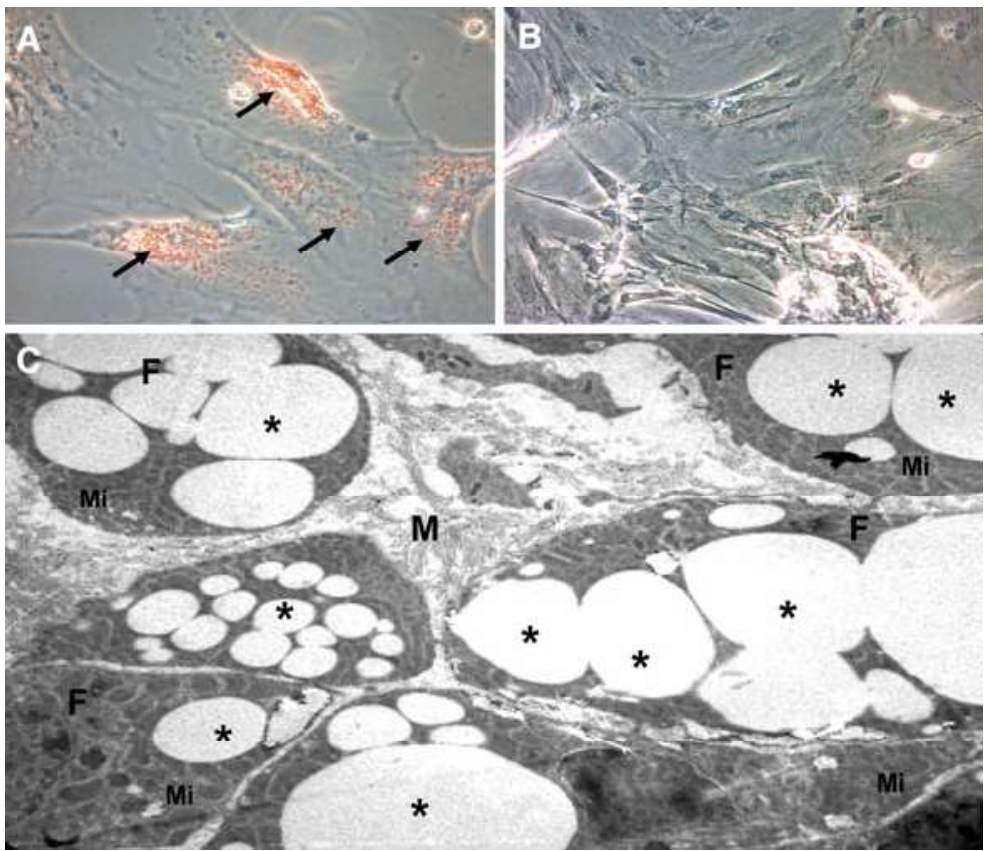

Fig. 5 a-b Light microscopic demonstration of adipose tissue formation with Oil Red O staining. In the monolayer cultures, treated with adipogenic induction media, abundant quantities of vacuoles can be observed in the cells (a). Oil Red O staining for fat revealed that these vacuoles contained neutral lipids (arrows). In contrast to this, control cells cultured for the same time period in normal culture medium containing 10\% FCS stained negative for fat vacuoles (b). Magnification: a-b $40 \times$. c Electron microscopic demonstration of the adipogenic

micromass pellet culture or high density culture, assumed a round, nodule like morphology already after 1 day in culture. Alcian blue staining after 14 days in culture revealed a high content of cartilage specific proteoglycans in induced cultures (Fig. 9a). It could be observed that alcian blue staining was more intense and uniform in the center of the cultures and decreased and became irregular towards the outer rim of the cultures, suggesting a higher content of cartilage specific proteoglycans in the inner part of the cultures. In contrast to this, control cultures cultured in chondrogenic induction medium without TGF $\beta-1$ or cultured in cell culture medium containing $10 \%$ FCS showed little or no alcian blue staining (Fig. 9b).

\section{Transmission electron microscopy (TEM)}

Transmission electron microscopic pictures of the chondrogenic-induced cultures revealed areas of cartilage like nodules, with rounded, chondrocyte-like morphology of the cells in the middle and inner layers of the nodule and a long elongated, fibroblast-like layer of cells surrounding the nodule similar to a perichondrium in vivo (Fig. 9c). These newly formed chondrocytes contained high amounts of glycogen, many cell organelles (rough ER, mitochondria, Golgi apparatus) and high quantities of euchromatin in the induced cMSCs. Transmission electron microscopic demonstration from the adipogenic stimulated cultures revealed the ultrastructural changes the cMSCs underwent while transforming into fat cells $(\mathbf{F})$. Cells are observed with high contents of lipid vacuoles (asterisks) in the cytoplasm and cell organelles (mitochondria) $(M i)$. The adipocytes $(F)$ produce extracellular matrix $(M)$ of collagen type I fibers. Magnification: $5.000 \times$

nucleus. Between these chondrocytes, abundant amounts of a very thin, fine and highly organized extra cellular matrix fibril network could be observed. In contrast the extracellular matrix deposited in the rim of the nodules between the fibroblast like cells was thicker and coarser. Contrary to these findings, in the control cultures, cultured with induction medium without $\operatorname{TGF} \beta-1$ and in the control cultures incubated with normal culture medium with $10 \%$ FCS signs of apoptosis (membrane blebbing, apoptotic bodies) (not shown) were observed, thus indicating the importance of TGF $\beta$ - 1 stimulation for chondrogenic development in these experiments.

\section{Immuno-transmission electron microscopy (ITEM)}

Immuno-transmission electron microscopy strengthened the obtained results and revealed the hyaline cartilage composition of the newly formed extracellular matrix. We found abundant amounts of collagen type II (Fig. 10a) and cartilage specific proteoglycans (CSPG) (Fig. 10b) in the matrix of the chondrogenic-induced cultures. As expected, gold labeling for the collagen type II is evenly distributed over the matrix, since collagen type II forms the basic matrix network for the cartilage matrix. On the other hand, labeling for the CSPG is bundled with a high 

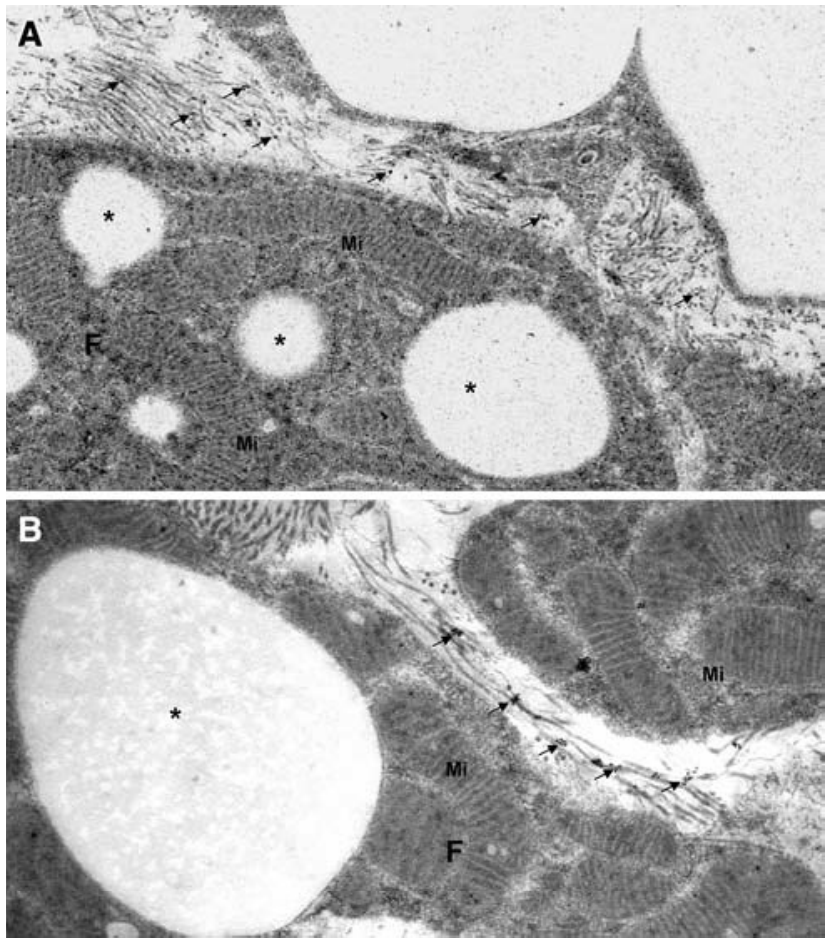

Fig. 6 a-b Immuno-electron microscopic demonstration of collagen type I and adiponectin in adipogenic induced cultures using immunogold labelling. a Immuno-labelling with anti-collagen type I antibody is demonstrated on the collagen fibrils (arrows) in the surroundings of the newly differentiated adipocytes. b Immuno-labelling with antiadiponectin antibody shows its distribution in the extracellular matrix. Magnification: a-b 20.000×
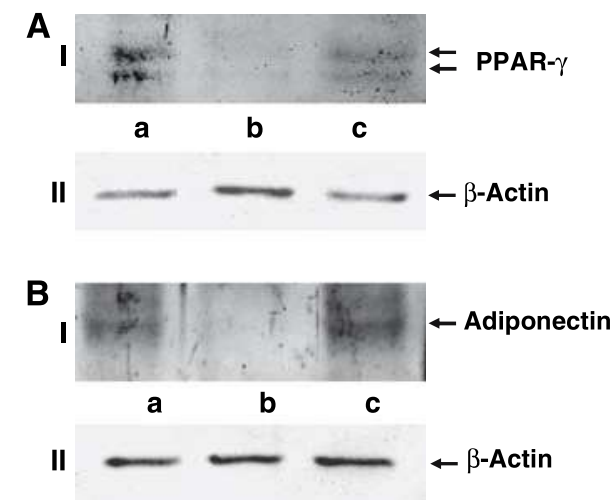

Fig. 7 a-b Western blot analysis of adipogenic induced cultures. Western blot analysis with whole cell extracts from monolayer cultures treated without (b) and with (a) adipogenic induction medium, and from a positive control of pure primary adipocyte cultures (c). Results of Western blot analysis revealed expression of PPAR $\gamma(A I)$ and adiponectin $(B I)$ in the adipogenic induced monolayer and positive control cultures $(A I-B I)$. In the negative control samples (without adipogenic induction medium), no expression of PPAR $\gamma(A I)$ and adiponectin $(B I)$ could be detected. Expression of $\beta$-actin $(A I I-B I I)$ was not affected. Data shown are representative of three independent experiments

concentration in specific areas, indicating the strong incorporation of the CSPG between the mashes of the collagen type II net.
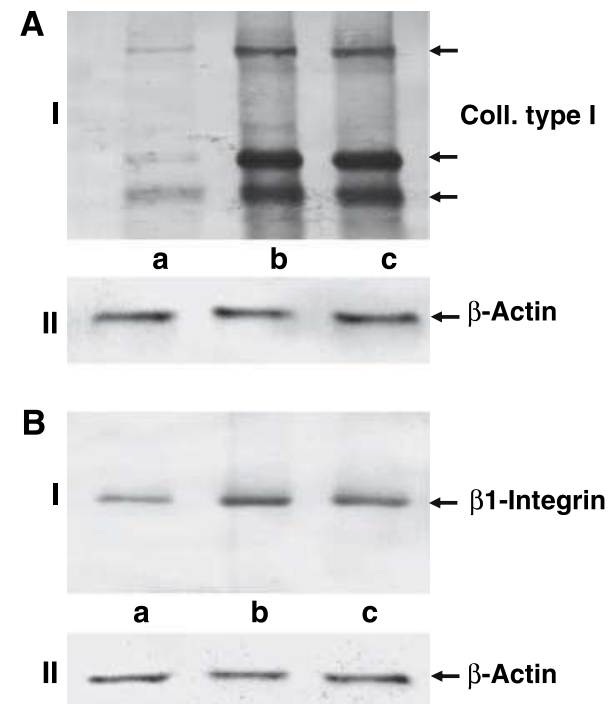

Fig. 8 a-b Western blot analysis with whole cell extract from monolayer cultures treated without (a) and with (b) adipogenic induction medium, and from a positive control of pure primary adipocyte cultures (c). Results of Western blot analysis revealed expression of collagen type $I(A I)$ and $\beta 1$-integrin $(B I)$ in the adipogenic induced monolayer and positive control cultures $(A I-B I)$. In the negative control samples (without adipogenic induction medium), a significantly weaker amount of collagen type I and $\beta 1$-integrin expression could be detected. Expression of $\beta$-actin $(A I I-B I I)$ was not affected. Data shown are representative of three independent experiments

\section{Western blot analysis}

To confirm the immunomorphological results described for the chondrogenic differentiation of the cMSCs and to analyze more precisely the chondrogenic differentiation of the cMSCs, whole cell extracts were probed for collagen type II, CSPG, $\beta 1$-integrins and Sox9 (Figs. 11, 12). In cultures treated with chondrogenic induction medium high amounts of collagen type II and cartilage specific proteoglycans (CSPG) could be detected (Fig. 11a/b-I), comparable to the detected amounts in primary chondrocytes that were cultured in high density culture. We observed no statistically significant difference in the detected amount of collagen type II and CPSG between the micromass pellet culture and the high density mass culture. Moreover, chondrogenicinduced cultures exhibited activation of the cartilage specific transcription factor Sox9 (Fig. 12b-I). Furthermore, the induced cultures, like the primary chondrocyte cultures, demonstrated high amounts of $\beta 1$-integrin (Fig. 12a-I). Our group has previously shown that $\beta 1$-integrins play an essential role in the maintenance and stabilizing of the chondrocyte phenotype, in chondrocyte-matrix interactions and in stabilizing the chondrogenic potential. This robust expression of $\beta 1$-integrin in the chondrogenicinduced cMSCs cultures underscores the fact that the 


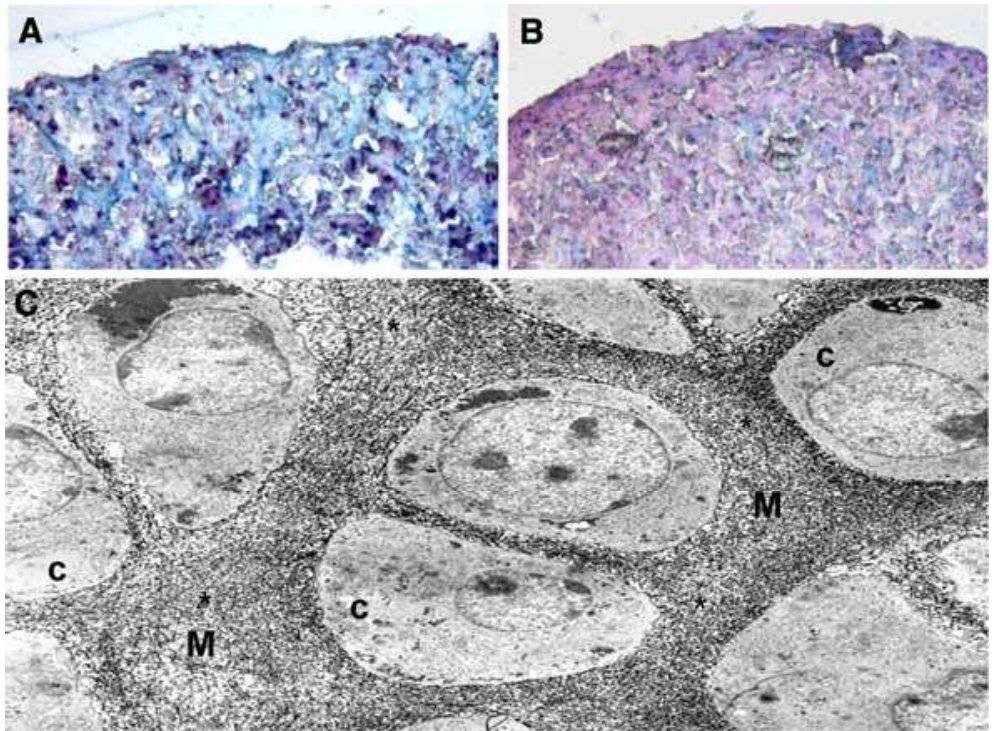

Fig. 9 a-b Light microscopic demonstration of cartilage tissue formation with alcian blue staining. After 14 days the high density cultures treated with chondrogenic induction medium (a) (treated with TGF $\beta$ 1 and dexamethasone) were intensely stained with alcian blue, revealing a high content of cartilage specific proteoglycans. In contrast to this, control cultures (b) cultured in induction medium without TGF $\beta$ 1 or cultured in normal culture medium containing $10 \%$ FCS showed little to no alcian blue staining. Magnification: $40 \times$. c Electron microscopic demonstration of the chondrogenic induced cMSCs in

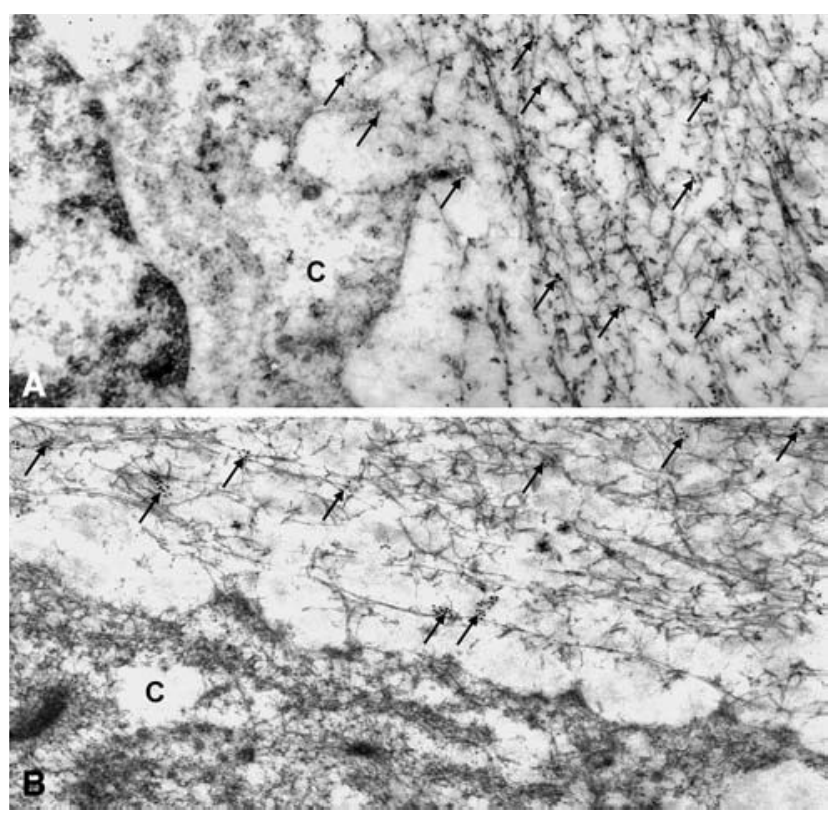

Fig. 10 a-b Transmission immuno-electron microscopic investigations of MSC cultures induced with chondrogenic induction medium in high-density culture. Chondrogenic induced cultures were immunogold labelled with anti-collagen type II (a) or anti-cartilage-specific proteoglycan antibodies (b). Anti-collagen type II immunogold-labelling (a) was evenly distributed on irregularly running fibrils of extracellular cartilage matrix (arrows). Anti-cartilage-specific proteoglycan labelled gold particles (b) formed clusters distributed irregularly in the extracellular matrix and on the cell surface (arrows). Magnification: $20,000 \times$ high-density culture. After 14 days, nodules with typical round or oval chondrocytes $(c)$ with small processes embedded in a network of extracellular matrix fibrils $(M)$ could be observed. Cells contained a well developed rough ER, mitochondria, other cell organelles, vacuoles and granules. These nodules, typical for cartilage formation, were surrounded by a layer of flattened, fibroblast-like cells embedded in fibrils of thick extracellular matrix similar to a perichondrium in vivo. Magnification: $5000 \times$

cMSCs differentiated towards chondrocytes and were capable of forming an adequate interaction between the cells and the matrix thus securing their survival and stabilizing their differentiated phenotype as chondrocytes. In contrast to this, in the control cells, cultured in chondrogenic induction medium without TGF $\beta$-1 or in cell culture medium containing $10 \%$ FCS, no collagen type II and no CSPG could be detected. This emphasizes the importance of TGF $\beta-1$ in chondrogenic differentiation of canine MSCs.

\section{Discusssion}

The present study demonstrated the multilineage differentiation potential of isolated adult canine bone marrow cMSCs in vitro at the ultrastructural and immunomorphological levels. We confirmed that these cells have MSC character and under appropriate culture conditions can effectively differentiate into functional osteoblasts, adipocytes and chondrocytes during in vitro development.

These conclusions are based on: (1) the expression of putative surface specific antigens, like $\mathrm{CD} 105^{+}$and $\mathrm{CD} 90^{+}$ as markers for MSCs and lacking of the hematopoetic stem cell markers $\mathrm{CD}^{-} 5^{-}$and $\mathrm{CD} 34^{-}$, (2) the appropriate response of cMSCs to adequate induction-components in the culture medium, (3) the newly differentiated cells 

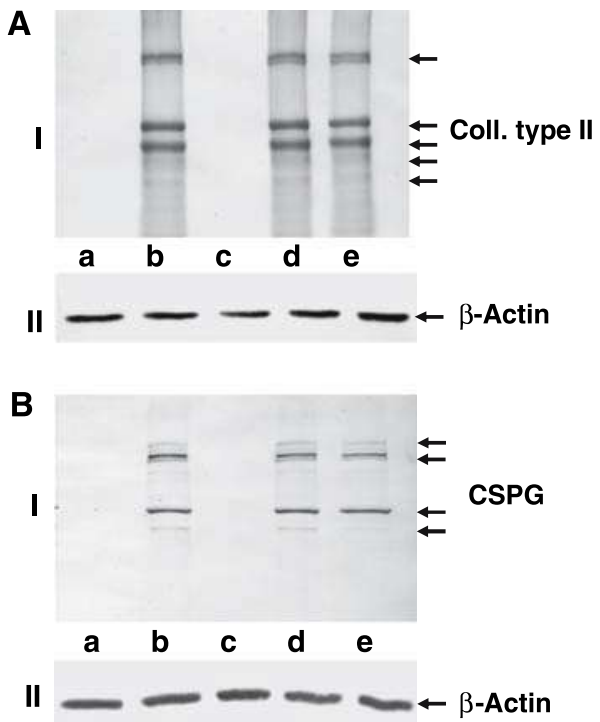

Fig. 11 a-b Western blot analysis of chondrogenic induced cultures. Western blot analysis with whole cell extracts from pellet cultures without (a) and with (b) chondrogenic induction medium, from high density cultures without (c) and with (d) chondrogenic induction medium and from a positive control of a pure primary chondrocyte culture (e). Results of Western blot analysis revealed high expression of collagen type II $(A I)$ and CSPG $(B I)$ in pellet and high density cultures treated with the chondrogenic induction medium and positive control cultures $(A I-B I)$. In the negative control samples (without chondrogenic induction medium), no expression of collagen type II $(A I)$ or CSPG $(B I)$ could be detected. Expression of $\beta$-actin $(A I I-B I I)$ was not affected. Data shown are representative of three independent experiments

A

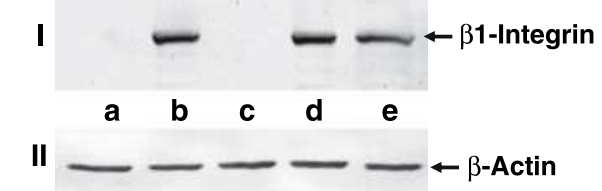

B

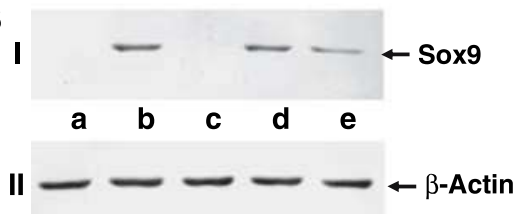

Fig. 12 a-b Western blot analysis of chondrogenic induced cultures. Western blot analysis with whole cell extracts from pellet cultures without (a) and with (b) chondrogenic induction medium, from high density cultures without (c) and with (d) chondrogenic induction medium and from a positive control of pure primary chondrocyte cultures (e). Results of Western blot analysis revealed high expression of $\beta 1$ integrin $(A I)$ and Sox9 $(B I)$ in pellet and high density cultures treated with the chondrogenic induction medium and in the positive control cultures $(A I-B I)$. In the negative control samples (without chondrogenic induction medium), no expression of $\beta 1$-integrin $(A I)$ or Sox 9 $(B I)$ could be detected. Expression of $\beta$-actin $(A I I-B I I)$ was not affected. Data shown are representative of three independent experiments produced specific osteoblast-, adipocyte- and chondrocyteassociated molecular markers (Cbfa-1; PPAR- $\gamma$, and Sox9), (4) functionally very important specific extracellular matrix proteins, and (5) electron microscopic evaluation demonstrated on a cellular ultrastructural level the nature-like differentiation to different connective tissue cells.

For developing cell-based tissue engineering and autologous connective tissue transplants, the most important requirement is gaining sufficient numbers of differentiated cells. The best candidate cells for this purpose are MSCs, because they are multipotent and have a high proliferative capacity. Because there is no definitive marker to identify MSCs, the gold standard procedure to prove their stem cell identity is: (1) their adherence on cell culture plates after isolation, (2) their expression of specific markers, and (3) their differentiation potential to osteoblasts, adipocytes, and chondrocytes in vitro (Dominici et al. 2006). The first step to demonstrate the MSC character of our isolated canine bone marrow cells was therefore, to show that these cMSCs express the putative MSC markers. Like other studies (Mageed et al. 2007; Mareddy et al. 2007) we could show this important MSC characteristic of our isolated stem cells.

Although the osteogenic potential of cMSCs in vitro and their osteochondrogenic potential in vivo has been previously evaluated (Kadiyala et al. 1997), to our knowledge, no attempts have been made to drive these cells down the chondrogenic or adipogenic differentiation pathways. Furthermore, osteogenesis, adipogenesis and chondrogenesis of cMSCs has not been evaluated at the ultrastructural and immunomorpholgical levels with the use of transmission electron microscopy (TEM), immuno-transmission electron microscopy (ITEM) and Western blot analysis.

Treatment with the osteogenic induction medium, as previously described by Pittenger et al. (1999), led to a morphological change of the cMSCs from an elongated fibroblast-like cell type to shorter, cuboidal cells. Since in vivo glucocorticoids are involved in the bone-formation and bone-remodeling axis and mesenchymal stem cells are believed to be the source of osteoblasts in the postnatal organism, the osteogenic induction medium was supplemented with dexamethasone (Jaiswal et al. 1997; Baylink 1983; Owen and Friedenstein 1988). The newly differentiated osteoblasts produced mineralized nodules as was confirmed in the light microscope by positive von Kossa staining. Furthermore, ultrastructural analysis of these cultures revealed very active cells with a high content of euchromatin in the nucleus, a large number of cell organelles and large amounts of a thick, well organized extracellular matrix. Indeed, immunogold labeling of this matrix confirmed it to consist of collagen type I, the most abundant collagen in bone matrix and of osteocalcin, an osteoblast specific protein (Ducy 2000; Ducy et al. 2000). Furthermore, 
osteogenic matrix formation and genotypic osteogenic differentiation was further underlined by immunoblotting against collagen type I and the osteogenic specific transcription factor Cbfa-1 (Runx-2), as Cbfa-1 is the earliest available marker for osteogenesis (Ducy 2000; Katagiri and Takahashi 2002).

Adipogenic differentiation of the cMSCs was first confirmed by positive Oil Red O staining of the lipid vacuoles within the cells. TEM of the adipogenic-induced cultures revealed high amounts of fat vacuoles, mitochondria of the lamellar christae type and a very thin well organised extracellular matrix. Indeed, this extracellular matrix consisted of collagen type I as was confirmed by immunogold labeling. It is well known that adipocytes in vivo synthesize collagen type III that surrounds every adipocyte in vivo and embeds them in the connective tissue. However, it has been described that liver derived fat-storing cells in vitro produce both collagen type I and III (Moshage et al. 1990). In this study, we could show by TEM, ITEM and immunoblotting both collagen type I and $\beta 1$-integrin production. Furthermore, the adipocyte-specific transcription factor PPAR $-\gamma$ and the adipocyte specific protein adiponectin were detected, indicating genuine genotypic differentiation of the cMSCs to adipocytes. In fact, PPAR- $\gamma$ is not solely important for adipocyte differentiation, but also for stabilizing the metabolic function of differentiated adipocytes (Lazar 2002; Vidal-Puig et al. 1997). Adipogenesis was induced with insulin, dexamethasone and 3-isobutyl1-methylxanthin (IBMX). The precise mechanisms of action are not fully understood yet, although it is believed that lipid accumulation in the cells is mediated via the insulin/IGF-1, glucocorticoid and cAMP signaling pathways (Gregoire et al. 1998; Gregoire 2001).

Chondrogenesis could be demonstrated first of all through light microscopy evaluation by demonstrating abundant Alcian blue staining of cartilage specific proteoglycans (CSPG) in the differentiated cMSCs. In vivo, cartilage forms through the condensation of stem cells and enlarges through appositional growth by recruiting the cells from the outer layer into the chondrogenic lineage (Cancedda et al. 1995). Ultrastructural evaluation by TEM demonstrated morphological changing of the cMSCs into a typical chondrogenic phenotype. Cells became round and typical formation of chondrons was observed. Newly differentiated chondrocytes exhibited high amounts of euchromatin in the nucleus and an augmentation of cell organelles, indicating increased protein biosynthesis. This increased cellular activation was reflected in the production of large amounts of a thin, fine and highly organised extracellular matrix. These nodules, typical for cartilage formation, were surrounded by a layer of flattened, fibroblastlike cells embedded in fibrils of thick extracellular matrix similar to a perichondrium in vivo. Evaluation of the extracellular matrix in the nodules, by immunogold labeling, revealed col- lagen type II and CSPG content, underlining the hyaline cartilage character of the newly formed extracellular matrix. Immunoblotting further demonstrated chondrogenic differentiation of the cMSCs, as collagen type II, CSPG and the chondrogenic specific transcription factor Sox9 were detected. Furthermore, strong expression of $\beta 1$-integrin was detected. As our group has previously demonstrated $\beta 1$-integrin plays an essential role during chondrogenesis in the maintenance and stabilization of the chondrocyte phenotype and in chondrocyte-matrix interaction, stabilizes the cartilage specific character of the extracellular matrix (Shakibaei 1998; Shakibaei et al. 1993, 1995, 1997, 1999, 2001; Shakibaei and Merker 1999). This strong expression of $\beta 1$-integrin in the chondrogenic-induced cMSC cultures underlines, not only the fact that the cells differentiated towards a chondrocyte phenotype but also highlighted that they are capable of forming an adequate interaction between the cells and the matrix thus securing their survival and stabilizing their differentiated phenotype as chondrocytes. Chondrogenic induction was achieved with dexamethasone and $\operatorname{TGF} \beta 1$. TGF $\beta 1$ is well known to play an important part in chondrogenesis through upregulating the expression of extracellular matrix genes (Zhou et al. 2004; Dong et al. 2005). Dexamethasone alone has been described as a stimulator for chondrogenesis through positively influencing the upregulation of extracellular matrix genes and/or thorough enhancing their TGF $\beta 1$-mediated expression (Derfoul et al. 2006; Grigoriadis et al. 1988; Sekiya et al. 2001). However, in this study we found that dexamethasone alone is not sufficient as an inducer of chondrogenesis in cMSCs; but the external addition of TGF $\beta 1$ is essential for the chondrogenic induction of canine cMSCs.

In conclusion, the data presented has demonstrated, for the first time, that cMSCs possess multilineage potential and, when cultivated with the appropriate induction components, differentiate into highly specialized and functionally competent osteoblasts, adipocytes and chondrocytes. The resulting differentiated cells display ultrastructural features similar to resident cells in the original tissues as determined by ultrastructural and immunomorphological techniques. A deeper insight into the differentiation potential of cMSCs may help to promote the future use of cMSCs in regenerative medicine, since this tissue engineering approach has the benefit of creating an alternative biomaterial to be used as connective tissue substitutes for cell-based autologous reconstructive surgery.

Acknowledgments The authors would like to thank Ms. Karoline Fischer for her excellent technical assistance.

\section{References}

Alexanian AR, Sieber-Blum M (2003) Differentiating adult hippocampal stem cells into neural crest derivatives. Neuroscience 118:1-5 
Baylink DJ (1983) Glucocorticoid-induced osteoporosis. N Engl J Med 309:306-308

Bosnakovski D, Mizuno M, Kim G, Takagi S, Okumura M, Fujinaga $\mathrm{T}$ (2005) Isolation and multilineage differentiation of bovine bone marrow mesenchymal stem cells. Cell Tissue Res 319:243-253

Bottai D, Fiocco R, Gelain F, Defilippis L, Galli R, Gritti A, Vescovi LA (2003) Neural stem cells in the adult nervous system. J Hematother Stem Cell Res 12:655-670

Buck CA, Horwitz AF (1987) Integrin, a transmembrane glycoprotein complex mediating cell-substratum adhesion. J Cell Sci 8:231250

Cancedda R, Descalzi Cancedda F, Castagnola P (1995) Chondrocyte differentiation. Int Rev Cytol 159:265-358

Cancedda R, Dozin B, Giannoni P, Quarto R (2003) Tissue engineering and cell therapy of cartilage and bone. Matrix Biol 22:81-91

Caplan AI (1991) Mesenchymal stem cells. J Orthop Res 9:641-650

Caplan AI, Bruder SP (2001) Mesenchymal stem cells: building blocks for molecular medicine in the 21st century. Trends Mol Med 7:259-264

Caplan AI, Dennis JE (2006) Mesenchymal stem cells as trophic mediators. J Cell Biochem 98(5):1076-1084

Conget PA, Minguell JJ (1999) Phenotypical and functional properties of human bone marrow mesenchymal progenitor cells. J Cell Physiol 181:67-73

Derfoul A, Perkins GL, Hall DJ, Tuan RS (2006) Glucocorticoids promote chondrogenic differentiation of adult human mesenchymal stem cells by enhancing expression of cartilage extracellular matrix genes. Stem Cells 24:1487-1495

Dominici M, Le Blanc K, Mueller I, Slaper-Cortenbach I, Marini F, Krause D, Deans R, Keating A, Prockop D, Horwitz E (2006) Minimal criteria for defining multipotent mesenchymal stromal cells. The International Society for Cellular Therapy position statement. Cytotherapy 8:315-317

Dong Y, Drissi H, Chen M, Chen D, Zuscik MJ, Schwarz EM, O'Keefe RJ (2005) Wnt-mediated regulation of chondrocyte maturation: modulation by TGF-beta. J Cell Biochem 95:1057-1068

Ducy P (2000) Cbfa1: a molecular switch in osteoblast biology. Dev Dyn 219:461-471

Ducy P, Schinke T, Karsenty G (2000) The osteoblast: a sophisticated fibroblast under central surveillance. Science 289:1501-1504

Fortier LA, Nixon AJ, Williams J, Cable CS (1998) Isolation and chondrocytic differentiation of equine bone marrow-derived mesenchymal stem cells. Am J Vet Res 59:1182-1187

Fuchs E, Tumbar T, Guasch G (2004) Socializing with the neighbors: stem cells and their niche. Cell 116:769-778

Giordano A, Galderisi U, Marino IR (2007) From the laboratory bench to the patient's bedside: an update on clinical trials with mesenchymal stem cells. J Cell Physiol 211:27-35

Gregoire FM (2001) Adipocyte differentiation: from fibroblast to endocrine cell. Exp Biol Med (Maywood) 226:997-1002

Gregoire FM, Smas CM, Sul HS (1998) Understanding adipocyte differentiation. Physiol Rev 78:783-809

Grigoriadis AE, Heersche JN, Aubin JE (1988) Differentiation of muscle, fat, cartilage, and bone from progenitor cells present in a bone-derived clonal cell population: effect of dexamethasone. J Cell Biol 106:2139-2151

Harris MT, Butler DL, Boivin GP, Florer JB, Schantz EJ, Wenstrup RJ (2004) Mesenchymal stem cells used for rabbit tendon repair can form ectopic bone and express alkaline phosphatase activity in constructs. J Orthop Res 22:998-1003

Jaiswal N, Haynesworth SE, Caplan AI, Bruder SP (1997) Osteogenic differentiation of purified, culture-expanded human mesenchymal stem cells in vitro. J Cell Biochem 64:295-312

Johnstone B, Hering TM, Caplan AI, Goldberg VM, Yoo JU (1998) In vitro chondrogenesis of bone marrow-derived mesenchymal progenitor cells. Exp Cell Res 238:265-272
Kadiyala S, Young RG, Thiede MA, Bruder SP (1997) Culture expanded canine mesenchymal stem cells possess osteochondrogenic potential in vivo and in vitro. Cell Transplant 6:125-134

Katagiri T, Takahashi N (2002) Regulatory mechanisms of osteoblast and osteoclast differentiation. Oral Dis 8:147-159

Lazar MA (2002) Becoming fat. Genes Dev 16:1-5

Lee EH, Hui JH (2006) The potential of stem cells in orthopaedic surgery. J Bone Joint Surg 88:841-851

Leo AJ, Grande DA (2006) Mesenchymal stem cells in tissue engineering. Cells Tissues Organs 183:112-122

Mageed AS, Pietryga DW, DeHeer DH, West RA (2007) Isolation of large numbers of mesenchymal stem cells from the washings of bone marrow collection bags: characterization of fresh mesenchymal stem cells. Transplantation 83:1019-1026

Majumdar MK, Banks V, Peluso DP, Morris EA (2000) Isolation, characterization, and chondrogenic potential of human bone marrow-derived multipotential stromal cells. J Cell Physiol 185:98106

Mareddy S, Crawford R, Brooke G, Xiao Y (2007) Clonal isolation and characterization of bone marrow stromal cells from patients with osteoarthritis. Tissue Eng 13:819-829

Moshage H, Casini A, Lieber CS (1990) Acetaldehyde selectively stimulates collagen production in cultured rat liver fat-storing cells but not in hepatocytes. Hepatology (Baltimore, Md.) 12:511-518

Owen M, Friedenstein AJ (1988) Stromal stem cells: marrow-derived osteogenic precursors. Ciba Found Symp 136:42-60

Pittenger MF, Mackay AM, Beck SC, Jaiswal RK, Douglas R, Mosca JD, Moorman MA, Simonetti DW, Craig S, Marshak DR (1999) Multilineage potential of adult human mesenchymal stem cells. Science 284:143-147

Ringe J, Kaps C, Schmitt B, Buscher K, Bartel J, Smolian H, Schultz O, Burmester GR, Haupl T, Sittinger M (2002) Porcine mesenchymal stem cells. Induction of distinct mesenchymal cell lineages. Cell Tissue Res 307:321-327

Sekiya I, Koopman P, Tsuji K, Mertin S, Harley V, Yamada Y, Shinomiya K, Nifuji A, Noda M (2001) Dexamethasone enhances SOX9 expression in chondrocytes. J Endocrinol 169:573-579

Shakibaei M. (1998) Inhibition of chondrogenesis by integrin antibody in vitro. Exp Cell Res 240:95-106

Shakibaei M, Merker HJ (1999) Beta1-integrins in the cartilage matrix. Cell Tissue Res 296:565-573

Shakibaei M, Schroter-Kermani C, Merker HJ (1993) Matrix changes during long-term cultivation of cartilage (organoid or high-density cultures). Histol Histopathol 8:463-470

Shakibaei M, Zimmermann B, Merker HJ (1995) Changes in integrin expression during chondrogenesis in vitro: an immunomorphological study. J Histochem Cytochem 43:1061-1069

Shakibaei M, De Souza P, Merker HJ (1997) Integrin expression and collagen type II implicated in maintenance of chondrocyte shape in monolayer culture: an immunomorphological study. Cell Biol Int 21:115-125

Shakibaei M, John T, De Souza P, Rahmanzadeh R, Merker HJ (1999) Signal transduction by beta1 integrin receptors in human chondrocytes in vitro: collaboration with the insulin-like growth factor-I receptor. Biochem J 342(Pt 3):615-623

Shakibaei M, Schulze-Tanzil G, de Souza P, John T, Rahmanzadeh M, Rahmanzadeh R, Merker HJ (2001) Inhibition of mitogen-activated protein kinase kinase induces apoptosis of human chondrocytes. J Biol Chem 276:13289-13294

Till JE, McCulloch EA (1980) Hemopoietic stem cell differentiation. Biochim Biophys Acta 605:431-459

Tuan RS (2006) Stemming cartilage degeneration: adult mesenchymal stem cells as a cell source for articular cartilage tissue engineering. Arthritis Rheum 54:3075-3078 
Vidal-Puig AJ, Considine RV, Jimenez-Linan M, Werman A, Pories WJ, Caro JF, Flier JS (1997) Peroxisome proliferator-activated receptor gene expression in human tissues. Effects of obesity, weight loss, and regulation by insulin and glucocorticoids. J Clin Invest 99:2416-2422

Wickham MQ, Erickson GR, Gimble JM, Vail TP, Guilak F (2003) Multipotent stromal cells derived from the infrapatellar fat pad of the knee. Clin Orthop Relat Res 412:196-212

Williams JT, Southerland SS, Souza J, Calcutt AF, Cartledge RG (1999) Cells isolated from adult human skeletal muscle capable of differentiating into multiple mesodermal phenotypes. Am Surg 65:22-26

Zhou S, Eid K, Glowacki J (2004) Cooperation between TGF-beta and Wnt pathways during chondrocyte and adipocyte differentiation of human marrow stromal cells. J Bone Miner Res 19:463-470

Zuk PA, Zhu M, Mizuno H, Huang J, Futrell JW, Katz AJ, Benhaim P, Lorenz HP, Hedrick MH (2001) Multilineage cells from human adipose tissue: implications for cell-based therapies. Tissue Eng $7: 211-228$ 